РЫБАКОВ Андрей Вячеславович - доктор политических наук, профессор кафедры философии Московского авиационного института (Национального исследовательского университета) (125993, Россия, г. Москва, ГСП-3, Волоколамское ш., 4; rybackov@rambler.ru)

КВОН Даниил Андреевич - кандидат политических наук, доцент кафедры философии Московского авиационного института (Национального исследовательского университета) (125993, Россия, г. Москва, ГСП-3, Волоколамское ш., 4; docentkvon@yandex.ru)

\title{
КРИТЕРИИ ЭФФЕКТИВНОСТИ АСИММЕТРИЧНЫХ КРИЗИСНЫХ СТРАТЕГИЙ В УСЛОВИЯХ СОВРЕМЕННОЙ «ГИБРИДНОЙ ВОЙНЫ»
}

\begin{abstract}
Аннотация. В статье рассматриваются проблемы эффективности асимметричных кризисных стратегий в условиях современной «гибридной войны». «Гибридные войны» сегодня стали неотъемлемой частью новых геополитических реалий. Асимметричные стратегии вместе с превентивной дипломатией являются чрезвычайно актуальными инструментами мировой политики. Однако теория и практика асимметричного подхода в международных отношениях, несмотря на актуальность, разработана достаточно фрагментарно, особенно в вопросах классификации асимметричных стратегий и определении критериев их эффективности. Широкое использование асимметричного кризисного менеджмента стало неотьемлемой частью практики дипломатии, основой эффективного внедрения стратегии национальной безопасности любого суверенного государства, в т.ч. и России.
\end{abstract}

Ключевые слова: асимметричные стратегии, критерии эффективности, превентивный подход, «гибридные войны», кризисное урегулирование, кризисный менеджмент, международный терроризм, региональные конфликты

И нтерес к асимметрии как стратегической концепции впервые появился после окончания «холодной войны» в связи с перестройкой всей системы международной стабильности и безопасности, появлением принципиально новых, асимметричных по своей природе вызовов и угроз. Биполярная симметрия баланса сил эпохи «холодной войны» в значительной степени диктовала доминирование соответствующих симметричных национальных стратегий. Определяющей концепцией этого периода была концепция взаимного гарантированного уничтожения (Mutual Assured Distraction - MAD), которая была симметричной в своей основе для обеих сторон и, несмотря на все ее недостатки, обеспечивала стабильное балансирование на грани войны на протяжении почти 40 лет. Биполярная симметрия начала меняться лишь с появлением концепций стратегической обороны в космосе и национальной стратегической обороны территории (Strategic Defense Initiative, R. Reagan, 1983). Конец биполярного мира и окончание эпохи «холодной войны» вместе с появлением принципиально новых угроз и вызовов объективно стимулировали интерес к осмыслению роли и места асимметрии в структурах глобальной и национальной безопасности, системе международных отношений в целом. Асимметрия была и остается важным компонентом стратегического мышления. При этом чрезвычайно важным элементом является вопрос о том, какой характер имеет эта асимметрия - сознательный или обусловленный обстоятельствами (deliberate or default). В большинстве случаев как в прошлом, так и сегодня асимметрия стратегий была обусловлена прежде всего внешними, независимыми от игроков факторами естественными, техническими, историческими, экономическими, идеологическими и т.п. Сознательное использование асимметрии как средства получения 
стратегического преимущества - это уже высший пилотаж в исполнении выдающихся военных или политических деятелей на протяжении веков.

В конце 1990-х - начале нулевых годов появились многочисленные дефиниции асимметрии в политике и стратегии, которые в основном сводились к умению действовать «отличным от оппонента» образом или «вести борьбу нестандартными средствами» - не по правилам (not fighting fair) [Binnendijk 1998: 15]. Сегодня асимметричные стратегии широко используются многими государствами по всему спектру международных отношений, особенно в условиях так называемых гибридных войн. Асимметричный подход является неотъемлемой частью практики дипломатии и эффективного внедрения стратегии национальной безопасности любого суверенного государства, и России предстоит серьезно подумать над совершенствованием и использованием лучших образцов превентивных асимметричных стратегий для защиты своих национальных интересов, особенно в отношениях с Западом. Так, А.А. Кокошин отмечает: «Политика национальной безопасности - это в том числе меры по созданию симметричных и асимметричных проблем тому “оппоненту”, от которого исходят угрозы (вызовы) данному государству» [Кокошин 2017: 20].

В целом асимметрию в международных отношениях можно определить как «отсутствие тождественности между субъектами, наличными у них статусами, материальными и нематериальными ресурсами, тактиками и стратегиями международного поведения» [Дериглазова 2007: 127]. Наиболее адекватным на сегодняшний день, по нашему мнению, является определение, данное в одной из работ Института стратегических исследований США: «Асимметрия в военной сфере и сфере национальной безопасности - это умение действовать, организовывать свою деятельность и мыслить отличным от оппонентов образом с целью максимизации собственных преимуществ и использования уязвимых мест оппонента, захват инициативы или обеспечение пространства для маневрирования» [Metz, Jonson 2001: 5]. Несмотря на все недостатки и определенную тривиальность существующих определений, важным является акцент на нестандартности, революционном характере мышления, использовании нетрадиционных подходов, оперативных и технических решений, инновационных достижений в технике и технологии, неожиданности и организационной изысканности действий. Параллельно с развитием концептуального осмысления асимметрии шли попытки систематизации и классификации различных типов и видов асимметрий, асимметричных стратегий и сфер их возможного применения. Заметных успехов, однако, в этой сфере достигнуто не было. Преобладают примитивные дихотомические подходы полярного разделения очевидных факторов асимметрии. Наиболее часто выделяют:

- положительную и отрицательную асимметрию, т.е. асимметрия, которая используется в собственных целях, - положительная, а оппонентом - отрицательная;

- моральную и материальную асимметрию, т.е. асимметрию в области техники, вооружений, ресурсов или асимметрию в области психологии, идеологии, мотиваций и др.;

- количественную и качественную асимметрию;

- краткосрочную и долгосрочную асимметрию;

- частичную или интегральную асимметрию;

- сознательную или обусловленную обстоятельствами асимметрию;

- асимметрию с малой и большой степенью риска;

- асимметрию организационную и технологическую;

- асимметрию оперативную и тактическую.

Этот перечень дихотомических признаков (факторов асимметрии), очевидно, 
может быть продолжен и даже усовершенствован за счет введения адекватного ранжирования параметров, весовых коэффициентов или применения методов интеграции соответствующих показателей и факторов, однако он малопродуктивен как с теоретической, так и практической точки зрения. Анализ попыток систематизации и классификации признаков и факторов симметрии позволяют утверждать, что:

1) характеристики асимметрии и соответствующих асимметричных стратегий сложны и многомерны по своей природе и не могут быть описаны с помощью примитивных дихотомических делений;

2) ряд принципиально важных характеристик (факторов асимметрии) моральных, психологических, идеологических и др. - носят исключительно качественный характер и в принципе не поддаются дихотомическим или одномерным количественным оценкам;

3) отсутствие четких «правил игры», или «игра не по правилам», которая является ключевым признаком асимметричных стратегий, исключает возможность однозначной оценки их параметров и превращает разработку, оценку и имплементацию асимметричных стратегий скорее в искусство, чем в точную науку;

4) наиболее пригодным аппаратом описания и оценки асимметричных стратегий на сегодняшний день являются теория игр, экспертные процедуры и методы многомерной статистики, такие как факторный и кластерный анализы, которые позволяют представить и оценить параметры асимметричных стратегий в многомерном пространстве и, хотя бы частично, учесть влияние качественных факторов.

Обратимся к критериям эффективности асимметричных стратегий.

Анализ исторических истоков, концептуальных основ и классификационных параметров асимметричных стратегий позволяет перейти к формированию критериев эффективности и рекомендаций по применению этих стратегий, определяющих их дееспособность в сфере внешней политики и политики национальной безопасности.

Эффективные асимметричные стратегии должны:

1) быть необычными и непредсказуемыми в своей основе, носить инновационный характер, просматривать и подрывать устоявшиеся стратегические, тактические, организационные и оперативные основы и принципы;

2) быть направленными на наиболее уязвимые места и объекты оппонента, которые трудно или невозможно защитить, использовать методы и инструменты влияния, которые трудно предсказать или невозможно нейтрализовать;

3) носить творческий характер, а главное - воспринимать неопределенность и непредсказуемость действий соперника как неотъемлемую характеристику реальности, ориентироваться на высокоинтеллектуального оппонента, настроенного на использование асимметрии в собственных целях;

4) быть оптимально сбалансированными с точки зрения комплексного использования положительных и отрицательных элементов асимметрии; максимизировать собственные асимметричные преимущества и сильные стороны и минимизировать преимущества и сильные стороны оппонента; эффективно использовать факторы морального превосходства более слабой стороны, защищать свою территорию, веру, национальные ценности, идеалы от более сильного и агрессивного противника;

5) базироваться на совершенных (sophisticated) системах разведки и информационно-аналитического обеспечения, быть ориентированными не на текущий момент времени (тем более, не на прошлое), а на будущее, опираться на достоверные прогнозные разработки, учитывать вероятные изменения в силах и возможностях оппонента, его возможные меры и контрмеры; 
6) нести в себе угрозы и вызовы наиболее неизвестного и неопределенного для противника типа, которые способствовали бы его полной дезориентации;

7) быть неожиданными для соперника, надежно защищенными (засекреченными) в стадии разработки и имплементации, максимально способствовать повышению уровня неопределенности при принятии решений противником;

8) содержать в себе, учитывать тот факт, что асимметрия - это улица с двусторонним движением, поэтому разрабатывать ряд контрстратегий против вероятных угроз и ударов (в т.ч. асимметричных) по собственным уязвимым местам и центрам силы (contingency planning);

9) принимать во внимание возможные последствия и побочные эффекты (collateral damages) и «последствия последствий» имплементации как собственных стратегий, так и контрстратегий противника по принципу цикла: «стратегия - контрстратегия - контрконтрстратегия»;

10) быть максимально гибкими и адаптивными, включать в себя совершенные системы и механизмы постоянной коррекции и коррекции процессов имплементации стратегий по каналам обратной связи (feedback loops) с целью своевременного выявления и устранения недостатков имплементации, нейтрализации неожиданных и непредсказуемых событий, угроз и контрстратегий соперника.

Таковы основные критерии эффективности асимметричных стратегий и мер обеспечения национальной безопасности страны. Их имплементация в реальную политику позволит поддерживать суверенитет России и противостоять более сильным противникам, пусть и в духе макиавеллизма. Уже подчеркивалось, что квинтэссенция концепций асимметрии заключается во введении соперника в заблуждение при ведении борьбы «непредвиденными средствами», «не по правилам» (not fair). Война (игра) «по правилам», как и любые моральные ограничения, противоречит самой природе асимметричных стратегий. Это, однако, отнюдь не исключает существования самих правил. Правила могут быть. Однако они вляются разными для разных сторон. В свое время Мао Цзэдун так ответил своим японским противникам: «...вы ведете свою войну, а я буду вести свою». Принятие правил игры соперника, тем более сильного соперника, однозначно приводит к проигрышу. Это аксиома.

\section{Список литературы}

Дериглазова Л.В. 2007. Концепция асимметрии в теории и практике международных отношений. - Вестник Томского государственного университета. № 295. С. 123-129. Доступ: http://vital.lib.tsu.ru/vital/access/manager/Repository/ vtls:000474564 (проверено 02.07.2018).

Кокошин А.А. 2017. Методологические вопросы оценки угроз национальной безопасности. - Социс. Социологические исследования. № 11. С. 19-29.

Binnendijk H. 1998. Engaging Power for Peace: The 1998 Strategic Assessment. Wash., DC: National Defense University, Institute for National Strategic Studies. 283 p.

Metz S., Jonson D. 2001. Asymmetry and US Military Strategy: Definition Background and Strategic Concepts. Strategic Studies Institute. 30 p. 
RYBAKOV Andrei Vyacheslavovich, Dr.Sci. (Pol.Sci.), Professor of the Chair of Philosophy, Moscow Aviation Institute (National Research University) (4 Volokolamskoe Highway, Moscow, Russia, 125993; rybackov@ rambler.ru)

KWON Daniel Andreevich, Cand.Sci. (Pol.Sci.), Associate Professor of the Chair of Political Science, Moscow Aviation Institute (National Research University) (4 Volokolamskoe Highway, Moscow, Russia, 125993; docentkvon@yandex.ru)

\section{CRITERIA FOR THE EFFICIENCY OF ASYMMETRIC CRISIS STRATEGIES IN THE CONTEMPORARY HYBRID WAR}

Abstract. The article analyzes the problems of the asymmetric crisis strategies effectiveness under the conditions of the contemporary hybrid war. Hybrid wars today have become an integral part of the new geopolitical realities in the world. However, the absence of system approach to the theory and art of asymmetric crisis management, lack of foresight and clear effectiveness criteria still prevail.

The authors provide an analysis of methodology and conceptual backgrounds of the asymmetric crisis strategies approach to the international relations and international security policy. The special attention is paid to the effectiveness criteria of the asymmetric strategies, to the role of the early warning systems in the modern diplomacy and international relations as a whole.

Keywords: asymmetric strategies, crisis resolution, hybrid wars, criteria of effectiveness, asymmetric crisis management, early warning, regional conflicts

СИТНОВА Ирина Валерьевна - кандидат социологических наук, доцент кафедры гуманитарных и социально-экономических дисциллин Черноморского высшего военного морского училища им. П.С. Нахимова (299028, Россия, г. Севастополь, ул. Дыбенко, 1a; sitnova.irina@Gmail.com)

ПОЛЯКОВ Александр Александрович - капитан 2-го ранга, адбюнкт очной адъюнктуры Черноморского высшего военного морского училища им. П.С. Нахимова (299028, Россия, г. Севастополь, ул. Дыбенко, 1a; sansanich27@yandex.ru)

\section{ИНФОРМАЦИОННО-ПСИХОЛОГИЧЕСКОЕ ВОЗДЕЙСТВИЕ КАК ПРАКТИКА ВЕДЕНИЯ ВОЙН ЧЕТВЕРТОГО ПОКОЛЕНИЯ}

Аннотация. В статье рассматриваются теоретические основы ведения психологических войн 4-го поколения, проводится анализ принципов и приоритетов проведения информационно-психологических войн как практик ведения войн 4-го поколения.

Ключевые слова: информационно-психологическое воздействие, информационно-психологическая война, война четвертого поколения, изменение культурного кода

$\mathrm{K}$ аждое государство обладает уникальным культурным кодом (духовнопсихологической системой, национальной памятью), уникальным набором компонентов, которые влияют на выбор стратегии, предпочтение тех или иных вооруженных сил. Культурный код включает в себя целостную исторически сформированную систему бессознательных установок населения и бессознательную реакцию этого населения на ситуацию, связанную с угрозой для жизни, а также бессознательные инстинкты самосохранения нации в условиях аномии или потери идентичности (схожести), которые цементируют нацию как политический и социальный субъект. Элементами культурного кода являются стратегическая культура и национальные интересы. 